\title{
Interactive comment on "Implications on
} atmospheric dynamics and the effect on black carbon transport into the Eurasian Arctic based on the choice of land surface model schemes and reanalysis data in model simulations with WRF" by Carolina Cavazos Guerra et al.

C. $\mathrm{He}$

cenlinhe@atmos.ucla.edu

Received and published: 9 January 2017

The authors focused on the impacts of land surface models and meteorology data on black carbon (BC) transport into the Eurasian Arctic. The results are interesting. I have a short comment. over the Arctic are significantly affected by emissions (particularly flare emissions in 
Russia), BC scavenging by mixed-phase clouds, and aerosol dry deposition velocity over ice/snow. It would be very interesting and give readers a more complete picture, if the authors could add some discussions on this aspect to highlight potential uncertainty related to these factors.

\section{Reference}

Qi, L., Li, Q., Li, Y., and He, C.: Factors Controlling Black Carbon Distribution in the Arctic, Atmos. Chem. Phys. Discuss., doi:10.5194/acp-2016-707, 2016.

Interactive comment on Atmos. Chem. Phys. Discuss., doi:10.5194/acp-2016-942, 2016. 